\title{
Folk Art, Indigenous Knowledge Systems and Climate Change: An Assessment of Helpful Practices and Habits in Selected Communities in Cameroon
}

\author{
Donatus Fai Tangem \\ Department of Arts and Archeology, University of Yaoundé 1, Cameroon
}

*Corresponding Author: Donatus Fai Tangem, Department of Arts and Archeology, University of Yaoundé 1, Cameroon.Email: tdonatus@yahoo.com

\begin{abstract}
Although the expression "climate change" is relatively recent among indigenous people, the question of climatic variation and its related changes in temperature is not an unknown phenomenon among indigenous communities. Rather, such transmutations are part of the practical realities that orchestrate resilience and measures that ensure man's survival. Therefore indigenous or traditional wisdom abound on how communities deal with harsh consequences of climate change. For communities whose livelihood practices and habits relate directly with the ecological system, there can be no mistake as to how traditional knowledge systems are developed to cater for mother earth, the source of life and life related support systems. This paper thus sets out to streamline native ways by which some communities in Cameroon demonstrate appreciable consciousness about the question of climate change and also go further in adapting coping mechanism. With the aid of folk artists, relevant information and strategic principles are integrated in folk songs and performances organized by the communities for information dissemination. Through traditional belief systems, practices and habits, climate change and its harsh consequences on man and his environment are combatted with a degree of success. Through traditional wisdom and complex indigenous technics, changes in climate are met with working strategies from which the "civilized" "modern" and "progressive" societies need to draw lessons and also capitalize. Ranging from agriculture to livestock breeding, animal husbandry and human health, the disastrous effects of climate change have characteristically been unsparing. It is therefore against the background of the dreadful consequences of the monstrous phenomenon that the strengths and worth of indigenous knowledge systems call for attention and further adoption by governments and or international bodies critically involved in the search for survival mechanisms. In all, this paper is set against the theory of Environmental Determinism as propounded by Ellen Churchill Semple (1911) Ellsworth Huntington (1945)
\end{abstract}

Keywords: Folk Art, Indigenous knowledge, climate change, practices and habits.

The ravaging effect of climate change has inadvertently projected on the great potentialities of indigenous knowledge as a worthy factor in the collective struggle against the phenomenon. As noted, the theory of environmental determinism also known as climatic determinism endorses the argument that the physical environment affects the social and cultural development. It is therefore not strange that cultural practices shifts and adjust as a result. In some selected communities in Cameroon, the fight against climate change is better appreciated from the background of livelihood adjustment and strategic measures. With the objective of streamlining workable measures and adjustment developed from traditional wisdom, this paper points out ways by which indigenous knowledge systems are deployed to serve man and his environment. To exhaustively analyze the issues the paper will seek answers to the following questions:

- What is climate change?

- What is Indigenous knowledge?

- What are the measurable impacts of climate change in the various communities in Cameroon?

- What are the habits and practices that help in the fight against climate change?

- From traditional or indigenous stand point, what are the indicators of distortions that require rapid adjustments? 
- What forms of adjustment and measures point to the efficiency of indigenous knowledge systems in combating the monster?

- How does indigenous knowledge fit in to sustainable policy formulation?

- How has the folk artist been implicated in the struggles?

The colossal failures of measures and programs formulated to combat climate change have particularly been due to the absence of inclusive and holistic approach that capitalizes traditional wisdom. Additionally, the experience gathered from mistakes committed and misdemeanors recorded, enabled certain communities to develop in-built mechanism and adjustments that local governments only needed to adapt and promote. The case of Nkambe central Sub Division in Donga Mantung Division of the North West Region of Cameroon is particularly noteworthy with a record of historical blunders that forever altered livelihood activities in the region. Climate change has been defined as a long-term drastic modification of climatic conditions noticeable through increase in temperatures; decrease in precipitation. This alternation is a result of both natural mutations as well as due to man's activities. While no one disputes the natural causes of climate change, there is no gainsaying the huge contributions by man to the global phenomenon. Therefore, the dramatic mutations in and around Nkambe plateau as well as other communities in Cameroon is adequate testimony of man's destructive contribution to the wear and tear of the ecological system. In the struggle against climate change, folk or traditional artists have interposed their services and talents variously as communicators, propaganda agents, informants and or mouth pieces of the communities or spokes persons of the council of elders. In such positions, they have been famous is disseminating information and propagating good practices and coping mechanism in the face of climatic troubles.

\section{Trading Water Sources for Electricity Poles and Pastoral Breeding: A Review OF DANGEROUS ECONOMIC OPTIONS}

The present distressing aridity that now plagues the Nkambe plateau is the outcome of misguided economic behavioral pattern and practices. This problem is traceable to the early 70 's when the Cameroon government launched a rural electrification project that jumpstarted a high demand for electricity poles. Nkambe being essentially agriculturalist oriented area, the fall in demand for coffee coincided with increased demand for poles. Meanwhile Donga and Mantung Division is also the second largest cattle breeding area in the country. The combined impact of this twin economic options left very harmful imprints on the environment and particularly with regards to water supply. Unaware of the consequences of their drive, every household invested in the sector. It was even a recommended practice to burn heaps of grass covered beneath large farm ridges that constituted proper nurseries for eucalyptus seedlings.

Thirty years after, the indigenes saw the disappearance of lakes and fish ponds that had been reputed for harboring large quantity and quality of fish. This realization urged local councils to launch the famous operation "cut down eucalyptus around water sources and the fencing off of animals and breeding areas". This is how the local councils checked the increasing aridity caused by both livestock breeding and the water sucking species of trees that were planted around water catchments. Clearly, the acute water problems facing the people of Nkambe plateau is a sad indication of misguided and misdirected economic options, choices and actions. Nkambe plateau is situated in the far North West regions of Cameroon in the Donga-Mantung Division. It covers a vast surface area that is very fertile and proper for cash crop cultivation including tea. However, the major source of livelihood is farming and the area is also suitablefor the cultivation of yams, beans and maize. For a long time the economy of Nkambe depended principally on coffee and cocoa, cash crops that were produced essentially for export.

In the early 70 s, the price of coffee dropped so drastically that most farmers stop cultivation and turned attention to make-shift cultivation and animal husbandry. The potentials of this naturally dark and fertile soil of the area was further enhanced by the presence of several streams, springs, rivers and natural ponds and waterfalls. This condition favoured the blooming of savannah, which on its part turned out to be very attractive to cattle farmers and herds' men from as far as Adamawa regions of Cameroon.The global fall in the demand and consequential drop in incentive for coffee production constituted a water shade for what followed. Meanwhile subsistent farmers had to look elsewhere for 
sustenance, the huge and increasing demand for electricity poles came a source of hope. In a kind of volcanic show of solidarity, every household sat up and with the help of some 'informed' agropastoral technical extension workers, specie of eucalyptus tree nurseries were set up all over the region. Although science and research establishes that there are over seven hundred species of the eucalyptus trees whose origins are traceable to Western Australia, our focus is on the "mallet" type. The mallet is a small to medium-sized tree with a relatively long trunk and very suitable for use as electricity poles. By its very nature, eucalyptus trees are generally very resistant to pest as its leaves are even processed and used for pesticides. Additionally, eucalyptus flower produce a great abundance of nectar, providing good food for many pollinators including insects, birds and bats. It is thus these immeasurable, but one sided view that the few and half-baked agricultural technician viewed the eucalyptus as a bailout from poverty and misery. Bee farming thrived as farmers made money from the sale of honey. At some point, honey from the region was considered to be of better quality due to the nectar from the eucalyptus trees.

Outside their immediate ranges, these trees are a mixed glory. Just as they offer hope for their beneficial impact on a poor people, they are also a source of trouble owing to their rather strong water sucking potential. Actually, it has been argued that a mature Eucalyptus tree consumes close to seven thousand litters of water daily. But at the time of its introduction and popular acclamation as an anodyne of poverty, the indigents of the Nkambe plateau entertained no fears with regards to its negative ecological impact, after all, as already noted, the area was blessed with numerous streams that appear almost invincible. Besides all else, the Eucalyptus trees was hailed as worthy alternative to the (re)generation of the (natural) forests. It grows very fast and is comparatively easier to manage. Its diverse uses either as timber for the fabrication of chairs, cupboards, beds, tables or simply as a source of energy or firewood for cooking further enhanced its exciting reception among the poor. Interestingly, the local government had over fifteen thousand hectares of land where she planted, harvested and supplied wood, timber and seedlings to everyone in need. Households were even encouraged to set up nurseries so as to reduce the pressure on the heavily guarded government owned forest. Guards could be perceived everywhere in the eucalyptus forest. For quick result, eucalyptus seedling dealers were encouraged to burn selected sectors of farms where grass and shrubs were covered under huge ridges of soil that made for proper conditions for the germination of such seedlings. Even children and teenagers learnt the trade as a means to augment family and household incomes.

The people of Nkambe soon discovered that trees planted on the hills and elevated land surfaces generally took longer time to mature compared to those planted in valleys and around water catchments and springs. This is how the craze for quick bail from poverty urged indigenes to inundate water catchments and sources with the worse species of trees (known to be very suitable for land reclamation or the draining of swamps). Apart from the option of eucalyptus tree cultivation, Nkambe plateau with its blooming savannah fitted as a veritable haven for livestock breeding. Its relatively flat land and undulating sceneries attracted breeders from as far as the northern region of neighboring Nigeria. In the dry season, herdsmen flocked into Donga-Mantung which till date is reputed as the second highest suppliers of beef, cheese and pasteurized milk in Cameroon. Although the relationships between farmers and herdsmen were never proper and harmonious, there is little or no gainsaying the complementary functions they both owed each other. While the grazers are not too well received by local farmers owing to the destruction that cattle and goats cause to their crops, these subsistent farmers could also not deny the value and profit drawn from the presence of cattle that provides dung for use as manure. It has been proven through research and practical experience that a specie of vegetable, the huckleberry (which is the staple food of the indigenous people of Nkambe and beyond) grow better, faster and even taste better when nursed around areas frequently inhabited by cattle, sheep and goats.

The problems however, with this strange bed fellowship is the combined impact that either cattle rearing or crop cultivation and tree planting has on the water sources. Whether or not these same options generate economic fallouts and actually alleviated poverty is quite another ball game. But there is undeniable evidence that the combined pressure both by herdsmen and eucalyptus tree foresters was to have very devastating consequences for the indigenes. Barely over thirty years after their initiation in a domain they did not master and were also misdirected in their economic activities, 
the population of the Nkambe plateau rose to the sad realities of the drying up of streams, lakes, rivers and fish ponds. These had been viable and reputed for a rare selection and quantity of fish and other aquatic food sources. The point need not be stressed that the poor management of the people's economic choices and practices led above all else to poor health and sanitation conditions. Studies showed that, while the herdsmen and cattle breeders directed their animals straight into the streams and rivers for a drink of water, hardly did they consider the effects of their action on the downstream users of the same rivers. In some extreme cases, cattle breeders drilled holes and wells around catchment areas for the supply of drinking water for their animals. Such a practice over the years affected water supply and the hygienic conditions of even the same herdsmen who share same water sources with their animals. The consequential step up in water borne diseases coupled with scarcity of what constitute the source of livelihood, meant a catastrophe was in view for the people of the Nkambe plateau of the North West region of Cameroon.

\section{Salvation Measures and Survival Strategies}

Having measured and understood the hibernating catastrophe in delay around the entire region, the local councils sprang to its feet for prompt action. With immediate effect, a general campaign for the decongestion of water sources was launched. Out of fear and anxiety, the indigenes were implored to collectively join in the struggle against climate change, a reality that, though not really well understood, was nevertheless responded to differently by different people. However, everyone was unanimous on the fact that the eucalyptus trees planted in and around water sources was responsible for the drying and disappearance of certain animal and plant species besides the chronic water problem. With the same energy and conviction as it was in the era of its acclamation, the indigenes of the Nkambe plateau were prompted to deride and even out rightly decry the eucalyptus trees. The same product they hailed years earlier as a salvation plant was now despised as the cause of their misery.

Apart from clearing and liberating water catchments, the local council officers intensified sensitization campaign against the dangers of climate change. In this, a frontline campaign team was constituted and empowered to undertake a door to door campaign. In the workshop discussions that followed, agricultural extension workers and informed climate and environmentally conscious technicians exchanged views with farmers, cattle breeders and forest exploiters on the values of sustainable action. The role of folk artists in the affairs of the community could be measured in terms of information dissemination and all. Through music, song and dance, the traditional artists integrated climate change slogans and coping strategies in songs which they sand in public and social gatherings such as meeting groups, during celebrations and even during funeral ceremonies. To a very large extent, the noticeable change of practices and environmentally related habit was out self-conviction and the general campaign by local artists. While the council authorities imposed a simple levy on animal farmers whose animals were caught straying, the local population, regrouped under various organizations as indigenous women against climate change, Fons and traditional Rulers against climatic health hazard and youth against climate catastrophe.

In little groups, the local population engaged a rather assertive environmental consciousness that prompted the setting up of community laws and regulations against stray animals and deviant attitudes seen to impact negatively on the environment. In some selected communities and quarters, women and youth regrouped and designed projects which they submitted to international NGOS, and some specialized governmental institution for funding. Typical among these was the idea of community forestry management scheme. In yet other areas, projects were designed targeting water holes and the regeneration of the natural forest. Although few projects so far ever received funding, the local communities seemed to have engaged decidedly in a struggle that led to healthy environmental outlook. New habits and practices included the drastic cut in bush fires, a shift away from the traditional believe in burning farms before planting certain species of vegetable and crops. Apart from the water related crises to which the population of Nkambe central had been practical witnesses to, other noticeable manifestations of the impact of climate change were many and diverse. In a master degree research, Djibrill Ngala underscores that evidence of the devastating consequences of climate change around the Ndu Sub-division (and which holds true for Nkambe central) has been in such domains as decreasing crop yields, acute scarcity of pastures, soil erosion, loss of fertility and general rise in temperature. 
Folk Art, Indigenous Knowledge Systems and Climate Change: An Assessment of Helpful Practices and Habits in Selected Communities in Cameroon

It is against the foregoing that the role of indigenous knowledge within the frame work of climatic mutation is given proper attention through various articulations such as:

- The place of indigenous knowledge in meteorology: observation and interpretation of the climate.

- Economic adjustment and strategic mutations in livelihood practices.

- Auxiliary measures buoyed by social networks and collective governance.

- Belief systems, tradition, habits and cultural practices.

It is thus under these headlines or sub-titles that the worth of indigenous knowledge and both collective and individual practical action lay bare the true strategic values of coping mechanisms.

\section{The Place of Indigenous KnOWledge in Meteorology: ObServation and INTERPRETATION}

The question of over-reliance on the ecological systems for sustenance necessitated the development of traditional mechanism for weather forecast. In the Nkambeplateau, there are basically two broad seasonal realities; the rainy and the dry seasons. In-between these two seasons are characteristics occurrences and sign posts into which serious meaning is read. For the purpose of quick adjustment to the impending anthropogenic risks, every little sign and climatic features are carefully observed and interpreted.In prehistoric times, Pa Fine Boy and Ta Shey of Kungi village in Nkambe central, argue that certain characteristic occurrences such as land slide, ravaging tornadoes and serious floods were undisputed indicatorsof serious impending issues. These include the disappearance (death) of a chief, an influential personality in the community, or a fore warning of an impending catastrophe (measles, famine etc.) on the land. Therefore, in the event of any such happenings, fortune tellers, seers and community intercessors were immediately deployed to either avert the worse from happening or cushion the effect thereby mitigate the consequences. Through these indicators, complex traditional measures were taken and the related information disseminated throughout the communities for rapid and effective adjustments. In a way, such phenomenal occurrences were seen as historical makers about which even names of children were given in memory of the event or incident, a salutary practice that can help in the dating of events and situations of importance to the community.

Today, the pattern has drastically changed and so modified the orientation as well as perception of things. Within the context of transmutations that occur as a result of climate change, the focus of critical attention has been shifted in favor of other unmistakable signsand indicators. In some communities in Cameroon, certain species of trees are known to shed their leaves either prior to rainy season or towards the end of the dry season. However, when shedding occurs in between the expected time, then it foretells hash conditions that require quick adjustment to avert health hazards. Pa Fine Boy continues to argue that the observation of nature close-enough to note every minute alteration was a critical step in tracking down the consequences of climate change.Apart from the natural reaction of trees shedding leaves, there is the activities of certain species of migratory birds whose movements were quite meaningful. Time and experience had established dependable data based on the phenomenon of migratory birds. Its frequency or erratic migration also constituted hard information about which the communities made quick adjustment.

In Cameroon, the dragon fly is widely recognized as a harbinger of the dry season. Its appearance even in the middle of the rainy season foretells the relatively short period of rainfall. This information also calls for adjustment and measures needed to reduce the effect of erratic or scarcity of rain. Generally, rainfall is expected between the periods of March and late October. In the Nkambe plateau, early rains is sometimes considered bad omen. This is because sometimes farmers plant excitedly only to realize shortly after that the first or early rains had just been a fault-start, a rather deceptive down pour (that sometimes orchestrate serious crop failure.) owing to the fact after planting the rains ceased. Similarly, when rain fall is delayed sometimes it is indicative of prolonged period of rain that, depending on different soil types, may be an invitation for farmers to plant maize twice in a year. Although that possibility is rare for some communities, for others, it has been accepted as part of adjustment made to fill the gap left by poor harvest. However, as Ta Shey Fine Boy rightly indicates, climate change is more real and practically more devastating and distortive of natural calendar than the indigenous person can explain. His conclusion is that the distortion and disorientation of natural dispositions is practically noticeable among the phenomenon of cockcrows. Under normal condition, 
Ta Shey notes that, the crowing of cock signals the beginning of dawn. Thus in many communities, people depended on the first, second or third cock crows as indicators of time. This has been distorted such that the bright moon light in the middle if the night sometimes mislead the cocks. The foregoing shows by implication that traditional wisdom reserves something from which modern science can draw inspiration and better prepare combative measures like economic adjustments and change in livelihood activities.

\section{Economic Adjustments and Mutations in Livelihood Practices}

His royal highness, the Fon of kungi and traditional authority of the village once quipped that the devastating outcome of climatic variations have imposed adjustments and necessitated a review of livelihood activities. This statement, simplistic as it sounds indicates the profundity of the devastation orchestrated by the phenomenon of climatic mutations. When (Huntington, 1945). intimates that:

Climate stands first, not because it is the most important, but merely because it is the most fundamental. It is fundamental by reason of its vital influence upon the quantity and quality not only of man's food but most of his other resources and through its effect upon human occupations, modes of life, and habits, it is one of the main déterminants of culture. (34)

It stands to reason that culture and general ways of life is bound to be altered as a result of the phenomenon. The adjustments in practices and economic measures considered, it must be noted, are all indicators of the dynamism of traditional wisdom. Contrary to earlier believes that tradition and culture constituted obstacles to adaptation strategies and coping mechanisms, traditions and culture rather seem to contain internal adjustments and factors that prioritize life and sustenance. Focusing on certain shifts in practices, Djibrill Ngala argues that men and women undertook a redistribution of labour. Contrary to practices where by the men loitered at home playing games under the shades of baobab trees while the women spent all day in the fields and returned home with produce to cook and feed the family, Fon Budih of Kungi intimates that climate change has prompted a new culture of collective efforts to eke up family resources and ensure food self-sufficiency. Consequently the men now accompany their wives to the fields and farms where they practice greater diversification of agriculture. Thus away from the focus of mostly maize and beans that has been the traditional planting habits of most household, there is now an experimentation with other income generating crops and fruits that offer hope of financial autonomy. Explaining further, his royal highness Fon Budhi says when finally he made it to his farm, it occurred to him that they could demarcate the farm boundaries with certain species of trees which he later found out had serious medicinal values. Inadvertently, he found himself in a profound practice of agroforestry, a domain that even earned him more money than he had ever imagined. Realizing the benefits of his experiment, he initiated himself into back- yard gardening that equally resulted into blooming germination of a variety of spices like pepper, leeks, cabbage and garden-eggs. He reiterates that:

As a primary school teacher, I was prompted and pushed by the force and pressures of the time to experiment what I had been teaching children. Then I found that there were greater values in what I had been teaching than I was aware of. Surprisingly, when the village council met and I tried to introduce and encourage people into the idea of agroforestry and crop diversification, many of my councilors had already been practicing it with even better results than what I was so proud of.

Other interesting adjustments noted in Kungi village are in the domain of livestock and general animal husbandry. Due to increasing scarcity of pastures, herd's men and sheep/ goat farmers regrouped and jointly negotiated grazing land for both cattle and goats. Thus grazers integrated goats and sheep into their flocks thereby reducing domestic problems of hygiene and sanitation that had been escalated by goats and sheep that had hitherto been lodged domestically in many neighborhoods. In the end, the goats and sheep fared on even better after experimental de-domestication of the animals. In other areas fish farmers paired with pig farmers for a joint coordination. Pa TantohNformi explains:

Our struggles for the improvement of our condition led us to the realization that the excrement of pigs is good feed for fish. We thus built structures whereby the pig fence is constructed directly above the fish pond. This means, as the pig defecates, it falls directly into the pond where fish stay in wait. Therefore, by feeding the pig, one was indirectly also feeding the fish. 
Interestingly, fish farmer regroup with pig farmers for a win-win coalition that reinforce peaceful coexistence in the community. To draw the most from this, a division of labour is done and a time table is drawn and scrupulously respected for feeding the animals and cleaning the fence and the immediate surroundings.

What stands out very clearly in the coping mechanisms is that adjustments and shifts in habits and practices are done based on the need of the individual. This is to say that indigenous knowledge and traditional wisdom is activated based on the particular case and prevailing condition. For example, a herds man who gave his name simply as Adamu, shared his views on personal efforts to meet the challenges of climate change on the health condition of his livestock. Apart from transhumance, a practice where by herdsmen move from their permanent site to valleys or wet lands in search of green and fresh pastures, he has had to research and find herbs that sustain his cattle during the dry season when pure water and pasture are both scarce with the risk of epidemic outbreak among the cattle.With the help of prophylactic treatment that he administers, his cattle is able to cope with the harsh conditions pending the return of the rainy season when they pick up growth again. In his own findings, Djibrilla Ngala notes that "cattle farmers are modifying traditional pastoral activities by growing imported pastures such as the 'quatamala' and "brachiara" to fatten animals during the long dry seasons"( 14).

Other adjustments and practices are in the domain of energy management whereby people in the community resort to saw dust for cocking so as to cut down the pressure inflicted on the remnants of the natural forest often exploited for firewood. This shift considerably reduced the use of firewood. In line with action meant to ensure afforestation, many households are actively involved in the planting of the environmentally friendly trees including palm and raffia bush that offers reliable source of palm wine that is widely consumed and also used in preparing medicine for treatment of certain diseases. In his discourse on the adaptation strategies in Ndu sub-division, Shufai Njilangutong of Fuh village argues for the massive planting of raffia bush.

The first possible solution to the problem is for us all to start planting raffia bushes in area we had earlier considered too cold for the plant. Since global warming now rendered the earth more favorable to the plant. This experiment is working in Ndu highland very positively. This area had all along been considered as very cold and unfriendly to raffia plant.

The raffia bush, it must be said provide sustainable alternative to forest product such as wood needed for diverse household use. Shufai stresses the immeasurable value of raffia bush to satisfy more than the household needs that goes beyond its water generating potentials. In and around Nkambe and Ndu, the raffia bush offers fresh hope for forest regeneration, a factor deemed very crucial in the fight against climate change. Regarding the economic factor, the raffia bush is a source of palm wine that is used variously in traditional marriages, funeral rites, rituals, social and for commercial purpose. The production and sale of palm wine is a sure and steady source of finance to sustain the household and ensure financial independence. As it stands, strategic mutations in livelihood activities and economic adjustments, enable community members to explore and exploit the human and as well as natural potential to the fullest. Given that experience is the best teacher, the drastic consequences of blunders registered in the 70s have permanently been a sad reminder of the dangers of ignorance and the risk of unreasonable adventures. However, the incidence inspired and motivated the expansion and operational context of indigenous knowledge in the face of drastic climatic change.

\section{Auxiliary Measures Buoyed by Social Networks and Collective Governance}

In continuous efforts to erect concrete resilience as indigenous response to the detested phenomenal hazards of climatic variation, indigenous communities resorted to measures and network solutions. As if to galvanize and tightly secure collective respect of the recue measures put in place, Fon Budih opines that:

For the sake of our collective survival, we undertook to greatly honour the slogan "All for one, one for all". This traditional oath was a way to oblige members of the community to share ideas and any information they got patterning to climate change and adaptation measures. 
Since in traditional communities there is no question of author's rights, knowledge and information are considered public community utility about which selfishness or greed is anathema. As a follow up, community council meetings are propitious opportunities to share information and cross fertilize ideas that may only need experimentation. In this light, community and social networks are encouraged for their collectivity and sense of communal livelihood. Through such networks as bee farmers association, association of cocoa producers etc, communities copy and apply women's examples of social networks, 'njangis' and other regroupings that guarantee togetherness and mutual interdependence. Through these groups, training opportunities and funding possibilities are easily available sometimes through credit unions or non-governmental organizations, NGOs and international bodies. The case of Babanki women association is particularly interesting. In the Babanki sub division of Fundong of the North West region, the pass-it-On initiative enables association members to draw sustainable benefits from any project initiated in the group. In 2012, the "One woman, One piglet" initiative enabled the over 45 members of the group to own a piglet which they all raised following strict respect of the principle and information gotten from the training seminars. The initiative that was code named "Operation try other options" was an initiative designed to introduce women into animal husbandry, \{that had hitherto been seen as the men's monopoly\}.

In Kungi village the "Bufah Women" undertake to assist individuals in farm work. Aware of the African dictum that "collective effort make work lighter", these women developed a scheme that enable farmers to occupy and effectively cultivate vast farm holdings on which they plant various crops. As a matter of fact, mix cropping enable farmers after harvesting periods to end up with surplus and enviable variety from which they sell some to increase family resource thereby combat poor living standards. In some cases, farmers' cooperatives like the North West farmers' cooperative enable farmers to access loan or credit facilities that go a long way to jumpstart financial autonomy leading to improvement of living standards. In the long run, the sad consequences of climate change like low crop yield, famine and poor health that escalate poverty is quickly halted and transformed into opportunities for growth and stability, thanks to indigenous initiative and organizational power of the community leadership.

Closely attached to social network is collective governance initiatives that pool the competencies of all community members for the sustainable management of all resources in the community. In Nkambe central, the "Mangub community Water Scheme" is the concern of all and sundry. This water project was developed following the water crises of the 90s which exposed the shortsightedness of members of the community who, in a mad rush for financial gains, planted water sucking eucalyptus trees near water catchments. After the streams dried up leaving the people without water, it became clear to every community member what their collective errors had been. The resolve to collective manage the project after donor organizations sponsored the drilling of water holes, was much stronger. Having been fooled once and induced into a dangerous option, the Mangub community decisively woke up with a determined spirit to mitigate climate change effects, both on the land and in the life of community members.

Similar community management and collective governance is operational around the forest reserve that spans across three village communities of Binshua, Binka and Tabenken in Nkambe central. The forest that is now considered the identity of the above three villages is collectively managed by representative from the three villages in question. The positive outcome of this initiative is the considerably reduced exploitative attack by members and nonmembers of the identified communities whose sense of environmental awareness is enhanced by training and experience. Although the forest is endowed with rare species of trees and plants that are used for medicinal purpose, the community governance scheme set afoot a possible operational time schedule for any activity to be carried out in the forest. Herbalist and other community members desirous of access permits into the forest were expected to pay a fee and then take an oath to stay within the limit of their declared action. Even so, visits to the forest was guided by guards and persons recruited to oversee every visitors' action and movement and then make comprehensive reports to the governing body. Pa Wislar Nformi, a notable of Binshua village explains that the evaluation and report by the forest guard were taken seriously as any violation of the terms attracted high fines. Furthermore, the community forest management council draws up a calendar that stipulated the time of the year when visits and exploitation of the forest was allowed. Given that harmful, destructive forestry exploitation can easily be arrested and 
even mitigated during the rainy season, access permits were often issued during the wet periods. Therefore, herbalists were often advised to group and decide on the particular time during the rainy season that they intended to visit and exploit the forest. When particular plants or tree species were seen to be in high demand, the fee for such plants or herbs were slightly higher. Pa Wislar explains that in some situations, the community sponsored research on how to plant and nurture the particular tree species in high demand.

Concerning hunting in the forest, the coordination team made public a list of protected animal species. This list was often established and renewed each year in conjunction with state principles and laws put in place by the ministry of forestry and nature protection. As is the case with forestry exploitation, hunting periods were made public thereby allowing potential hunters enough planning time to apply for permits within the period allowed. In this way serious and effective central and checking mechanisms were set up to track down violators and limit adventurous forest exploitation that lead to destruction of the remnants of the natural ecological systems whose importance no one can doubt. The effectiveness of the community forest management scheme set down by the local community authorities suffered certain setbacks at the beginning of the 2012 calendar year. When the government of Cameroon launched the recruitment of agroforestry workers, the community volunteers serving as guards and overseers found gainful employment opportunities and left. The departure of these young and dynamic community members left a devastating gap in the effective protection of the community forest. As expected, the forest fell back into the waiting arms of heartless and lawless exploiters who immediately toppled the entire initiative and consequently opened the flood gate of anarchical forest exploitation.To stem the tide of the increasing anarchy, the traditional council resorted to the use of "kwifon", the uncompromising traditional authority that is often viewed as the judicial wing of the traditional set up equivalent to the police and gendarmerie force. The 'Kwifon' is endowed with strong powers to curse (as punitive measures) anyone guilty of any offence of intentional violation. The use of this arm of the traditional structure halted the lawless exploitation but could not be sustainable as a deterrent force due to various forms of interventions that resulted from its punitive measures on defaulters.

What is noteworthy however is the fact that, indigenous mechanism for checking excesses including environmental lawlessness is clearly available in the traditional settings of selected communities in the country. This initiative and operational approach confirmed and validated indigenous knowledge system as complete enough with inherent pillars strong enough to withstand the various challenges of the sociopolitical, economic and cultural exigencies. In this, climate change and adaptation plus circumstantial measures for resilience are not in any short supply. After all, traditional culture and belief system have, and do play great roles in handling and ensuring balance in the unfolding of societal issues.

\section{Belief Systems, Traditional and Cultural Practices}

A quick review of the power of indigenous knowledge and its adaptability to the unfolding of societal affairs point to the great role that tradition, culture and belief systems play in the re-enforcement of checking mechanisms. In this, the world views and general perceptions define and orientate community action and reaction to the socio political and economic challenges. This is how climate change related problems find easy solutions within the traditional ambit. For example, in the Kungi fondom, the phenomenon of ritualistic performances and libation requires that certain households own groves and places of worship which serve as ideal spots for interconnection and communication with the ancestors in the spirit world. Where such ideal spots happens to be the black, thick and natural forest, the environment becomes more or less untouchable reserve with its fauna and flora that is guarded and jealously preserved. Access to such area is regulated and limited to the few initiated who recognize and perform the duties they owe to the ancestors represented by the grove and ritual sites. Among other responsibilities, those initiated understand and respect the limit of any action they may be called to carry out or play in such places. His royal highness the Fon of Kungi adds that any action that does not fit fundamentally into the dreams and aspiration of the people are strictly prohibited. Since the grove or "bad bush" is sacred, animals, like trees therein are considered to be very special and are seen as the life force of the community. Thus animals in such places are hardly available to be hunted. Explaining the special nature of these animals, Pa Wislar says: 
In traditional community setup, the Fons and some very powerful notables have different totems. These totems generally have as particular habitat, the grove and ritual site or the forest. Since no one is allowed to question anybody about their totemic life, it is safer to "respect" any animal or bird seen around the ritual site. After all it is said that any attempt to capture them is analogous to threatening some one's life (through his totem)

The general consideration that traditional authorities have a variety of totems further scare people from daring any animal seen around sacred places and ritual site. This is also true with trees and other plants or even shrubs that grow in and around such sites. To cut any tree or harvest any herbs, some forms of incantations are performed in supplication of the gods and also in request for permission. There is therefore no argument about the value of such belief systems, tradition and culture in the context of climate change and the question of indigenous initiative to preserve the ecological system as a way of halting global warming. To indigenous people like the pygmies, their belief system and life style fevour environmental preservation thereby promoting green development.These people consider the forest as part and parcel of their identity and preferred habitat. Explaining the place of the forest in their livelihood activities, Zachariah Ngimba a pygmy herbalist holds that:

The forest is our heritage and identity marker. There is hardly an environment that is more comfortable than our natural forest habitat. The forest environment is the natural guarantor of hope, peace and happiness to forest dwellers. We therefore owe it as a sacred duty to protect and preserve the forest.

The implication of the foregoing is that by leaving in and around the forest, pygmies owe and actually do perform the expected responsibilities of preserving and guarding against any action seen to be harmful to the environmental setup. To support these claims, Zachariah points out that by their nature, pygmies do not seek leisure at the expense of their natural environment. They would hardly cut down trees and bulldoze land only to build pleasure parks. To the pygmies, any action on the environmental properties of fauna or flora must be motivated by inevitable need grounded in life sustenance. That means in their cultural practice and habit, the forest is not exploited indiscriminately. Zachariah states that the pygmies owe it to their off springs to bequeath dense and sumptuous environment to their children. He adds that their children right to access and enjoy the resources of their natural environment is only legitimate. It follows therefore, that it is their responsibility to ensure it is nonnegotiable. He stresses that:

Just as the generation before them preserved a wealthy forest environment for their sustenance, they are expected by right and as a duty to do same for their children and their children's children. Failure to perform their role is compared to unpardonable betrayal of once duty to the generations unknown. That act, I must tell you is punishable even by death.

The strategy which pygmies adopt besides their tradition and customary practices is to set aside a part, or sections of the forest for their children. This means that habitually, pygmies identify a buffer zone, a no go area that they reserve for the next generation. This is to further say that the inheritance they prepare and preserve for the welfare of their children is the forest, an environmental heritage. While the modern and civilized communities built mansions, accumulate financial resources that most often than not are a result of environmental destruction, pygmies simply preserve the raw environment with its natural endowment for the next generation. Reacting to the question of damages that their stay on the forest causes, Ngimba explains with disguised anger that:

No one understands the need to preserve the forest environment better than those of us who live there. Preservation for us is a culture. It is our way of life. We do not engage in environmental preservation or forest generation as a project. It is a way of life, a way of life, if you know what I mean. After all, is that forest not our raison d'etre? You see, our creator leaves in the forest, we believe and so it is a moral duty to keep the forest environment as natural as you met it.

The pygmy goes on to regret what he sees as paradox or the incongruities between government declaration and action. This paradox, he says is better measured through the authorizations issued to multiple logging companies. Accordingly, trees have more values to the pygmy community when it is 
standing than when it is cut.Once cut, trees have practically no value, he insists. It can then be seen that pygmies have no use for planks, on the quantities that modern men and civilized people do. Not only do they not build bridges the way we do, they also do not have any use for widely constructed roads. All they require is a foot path through the dense rain forest where they live and try to practice sustainable exploitation.

\title{
7. The Implication of Folk ARTISTS In the Struggles Against Climate Change
}

In full keeping with the changing times, folk artist have carefully trimmed and shaped their music content to address burning societal issues including climate change. Siding with the community and in order to push and valorize collective effort, the artist uses his art variously to propagate working strategies as well as decry and even lampoon inaptitude as well as detractors of community initiative. This is the focus of Morning Safari Art Group of Nkambe which elected to serve the community as communication agent. Focusing its musical display on current societal issues, the Morning Safari Art Group integrated climate change and education of the girl child as priority themes. To inform the community on the harsh realities of climate change, the group of artist creates songs that articulate such issues as scarcity of fruits, food and clean water in the community. While relating them to climate change, the artists also spell out how man must take responsibility for the phenomenon. As a matter of fact, the artists join forces with the traditional council and work to promote and communicate acceptable adaptations and helpful practices that every community member needs to know. In one of its songs "Unity is strength", the morning Safari Art Group point out as follows

\begin{abstract}
How can you explain your solidarity action that earned you trouble and failure when you already know that unity is power and success is sure? How can you justify your ignorance after we duly informed you that your action of planting eucalyptus tree was dangerous and even life threatening? How can we be wrong when we already sow the wrong thing coming and gave warning sounds?
\end{abstract}

Conceived particularly to propagate information on the need for adaptation strategies, the group of artists made sure to fill their musical productions with realistic and factual accounts and instances of issues and problems resulting from climatic changes. Besides all else, the folk artists use the art to inform the community of collective decisions as well as point out any loopholes in a decision or agreement that needed collective resolve. Through repetition, analogy and other devices, folks artist leave no gaps in information dissemination especially as pattering to climate related changes and adjustments.A profile of the services that the folk artist render their communities include:

- Advocacy on climate change related adjustment;

- Man's role in the question of change change

- Cases and consequences of climate change;

- Mitigating strategies and the way forward;

- Communication agent and spokes persons for council of elders and the community.

In one if its songs they explain:

We have no interest of our own, other than that of the community. We own no voice of our own than that of the environment,

We see nothing for ourselves but for the sake of the communities our ears and eyes are for nothing, if they are not for the community, therefore, you do not as you think, but you obey what is right for the community. So curse in the ear that will not hear and curse is the eye that will not see.

Similarly, the "Tongwala" band in kumbo, a neighboring community to the wimbum (tribe) people of Ndu and Nkambe acts as community servant. Made up of a collection of modern and traditional artist, the group pays attention to community events and unfolding issues in the community. Then it makes its report in song and dance to the public for evaluation and relevant action. This is to say besides other contributions, indigenous practices and indigenous knowledge and action initiated in favor of the fight against climate change are real and result orientate. 


\section{CONCLUSION}

It is easy and understandable how folk arts, tradition, culture and belief system all have what it takes to live in a natural and healthy environment, thereby limiting any chance of global heights in temperatures. While indigenous knowledge systems are endowed with survival and coping mechanisms to win in the face of global warming, international organizations engage in imported strategies bereft of practical field realities. Thus, to properly set up sustainable approach and structure in the struggle against global warming and climate change, it is ideal to understand and integrate traditional wisdom from which science and scientific theories can draw everlasting benefits. The life of the pygmies that rather turn to question the essence of the so-called civilized people may also motivate science and social adjustment mechanisms that guarantee free, fair and transparent management of natural resources. All that remains therefore is for the "civilized" communities to stop, evaluate and question the essence of the livelihood options, activities, habits and practices that damage the ecosystems. This is to say the key factor in the struggle against climatic changes is the implication of indigenous knowledge system and practices in the design of strategies as well as in policy formulation.

\section{REFERENCES}

[1] Agrawal, A. Greener Pastures. Durham, Duke University Press. 1999.

[2] Arrhenius, S. The Anthropogenic Global Warming.In: Blast, J., (2010). The Seven Theories of Climate Change. The Heartland Institute, USA, 1896.

[3] Australian Greenhouse Office, Climate Change: An Australian Guide to the Science and Potential Impacts, edited by Barrie Pittock. 2003.

[4] Blaikie, P. Cannon, I. Davis, Wisner. B. At Risk: Natural Hazards, People's Vulnerability, and Disasters. New York, NY. Routledge, 1994.

[5] Chambers, R. Conway, G. Sustainable Rural Livelihoods; Practical Concepts for the 21st Century, IDS Discussion Paper, No. 296. 1992.

[6] Eiseneck, K. Stecker, R. An Action theory of Adaptation to Climate Change. Earth System governance working paper No. 13. Lund and Amsterdam: Earth System Governance Project. 2011.

[7] IPCC, Impacts, adaptation, and vulnerability; Contribution of Working Group II to the Fourth Assessment Report of the Intergovernmental Panel on Climate Change, Cambridge University Press, Cambridge. 2007.

[8] Lawson, J. European Energy Policy and the Transition to a Low-Carbon Economy, OECD Economics Department Working Papers No. 779, OECD, Paris. 2010.

[9] Molua, E. Turning up the heat on African Agriculture: The Impact of Climate Change on Cameroon's Agriculture. AFJARE Vol 2, 2008.

[10] Nzuma, J. Waithaka, M. Mulwa, R. Kyotalime, M. Nelson, G. (2010). Strategies for adapting to climate change in rural sub-Saharan Africa. International Food Policy Research Institute. Discussion Paper No 01013. P.2006.

[11] Semple, E. (1911) and Huntington, E. (1945). Theory of Environmental Determinism. In: Keto, D., (2012). Cinematic Geographies: Environmental Determinism in Film Analysis, Masters of Fine Arts in Science and Natural History Filmmaking, Montana State University. P. 5-8.

[12] Somorin, O. Climate impacts, forest-dependent rural livelihoods and adaptation strategies in Africa: A review. African Journal of Environmental Science and Technology Vol. 4(13), Special Review. 2010.

[13] Stern, N. and Treasury, B. The economics of climate change: the Stern review. Cambridge University Press, Cambridge. 2007.

[14] Susman, P. O'Keefe, P. Wisner, B. Global disasters: a radical interpretation. In Hewitt, K. ed. Interpretations of Calamity from the Viewpoint of Human Ecology. Allen and Unwin, Boston. P.1983.

\section{WEBOGRAPHY}

IFAD: http://www.ifad.org/events/op/ecosoc.htm. (Accessed in March 2015)

Personal Interviews conducted 14-16 February 2015

Pa Fine Boy, 65 years

Fon Budhi, 38 years 
Folk Art, Indigenous Knowledge Systems and Climate Change: An Assessment of Helpful Practices and Habits in Selected Communities in Cameroon

Ta Shey, 72 years

Zachariah Ngimba, 53 years

Pa Wislar Nformi, 64

\section{AUTHOR'S BIOGRAPHY}

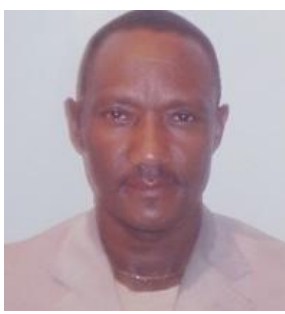

Donatus Fai Tangem (PhD), is lecturer of Drama/Theatre in the Department of Arts and Archeology, University Of Yaoundé 1. He is also a community development consultant and environmentalist interested in workshops /training on human rights, democracy and governance. One of his ground breaking projects is the British High commission sponsored venture code-named "The Cameroon Climate Change Road Show" an initiative that combined theatre performances with practical tree planting exercises. In this, Donatus wrote and directed a play entitled "Combating the Monster, Combating Chang", a play which through song, dance and dialogue radiate educative discourse on major concepts, theories and best practices in the struggle against climate change.

Citation: Donatus Fai Tangem. "Folk Art, Indigenous Knowledge Systems and Climate Change: An Assessment of Helpful Practices and Habits in Selected Communities in Cameroon." International Journal of Humanities Social Sciences and Education (IJHSSE), vol 4, no. 9, 2017, pp. 75-87. doi: http: //dx.doi.org/ 10.20431/2349-0381.0409010.

Copyright: (C) 2017 Authors. This is an open-access article distributed under the terms of the Creative Commons Attribution License, which permits unrestricted use, distribution, and reproduction in any medium, provided the original author and source are credited. 